Saudi Journal of Oral and Dental Research

Abbreviated Key Title: Saudi J Oral Dent Res

ISSN 2518-1300 (Print) |ISSN 2518-1297 (Online)

Scholars Middle East Publishers, Dubai, United Arab Emirates

Journal homepage: https://saudijournals.com

Review Article

\title{
Revascularization: An Update
}

Dr. Hamad Faries Al Munjem*, Dr. Hadi Yahay Al Bahesh, Dr. Abdullah Saleh Ali Alwalah

General Dentist Najran Specialist Dental Centre, Najran, Saudi Arabia

DOI: 1 10.36348/sjodr.2021.v06i01.016 | Received: 08.01.2021 | Accepted: 20.01.2021 | Published: 26.01 .2021

*Corresponding author: Dr. Hamad Faries Al Munjem

\section{Abstract}

Introduction: Endodontic management of young permanent teeth with necrotic pulp, with or without apical pathosis, positions numerous experimental trials. There is a risk of inducing a dentin wall fracture or extending gutta-percha into the periapical tissue during compaction of the root canal filling. Although the use of calcium hydroxide apexification techniques or the placement of mineral trioxide aggregate as an apical stop has the potential to minimize apical extrusion of filling material, they do little in adding strength to the dentin walls. It is a well-established fact that in reimplanted avulsed immature teeth, revascularization of the pulp followed by continued root development can occur under ideal circumstances. At one time it was believed that revascularization was not possible in immature permanent teeth that were infected. Methods: An in-depth search of the literature was undertaken to review articles concerned with regenerative procedures and revascularization and to glean recommendations regarding the indications, preferred medications, and methods of treatment currently practiced. Results: Disinfection of the root canal and stimulation of residual stem cells can induce formation of new hard tissue on the existing dentin wall and continued root development. Conclusions: Although the outcome of revascularization procedures remains somewhat unpredictable and the clinical management of these teeth is challenging, when successful, they are an improvement to treatment protocols that leave the roots short and the walls of the root canal thin and prone to fracture. They also leave the door open to other methods of treatment in addition to extraction, when they fail to achieve the desired result.

Keywords: Apexification, apexogenesis, immature permanent tooth, maturogenesis, mineral trioxide aggregate, regeneration, revascularization, revitalization, triple antibiotics.

Copyright (C) 2021 The Author(s): This is an open-access article distributed under the terms of the Creative Commons Attribution 4.0 International License (CC BY-NC 4.0) which permits unrestricted use, distribution, and reproduction in any medium for non-commercial use provided the original author and source are credited.

\section{INTRODUCTION}

Unlike fully developed teeth, pulp necrosis of an immature permanent tooth with apical inflammation does not preclude the presence of residual pulp progenitor cells in the apical third of the root canal. It does, however, create a situation where achieving the goals of conventional root canal treatment is not only difficult, but even when these are met, it leaves the root short, weak, and prone to fracture. Although some of the technical difficulties associated with conventional root canal treatment can be overcome when a calcium hydroxide $\left[\mathrm{Ca}(\mathrm{OH})_{2}\right]$ apexification approach or an apical plug of mineral trioxide aggregate (MTA) is used, the risk of future root fracture and tooth mobility because of a poor root-crown ratio still remains.

In the retrospective clinical study by Cvek, the frequency of cervical root fractures was markedly higher in endodontically treated immature teeth than in mature teeth and ranged in incidence from $28 \%-77 \%$, in accordance with the stage of root development. This finding emphasized the importance of preserving pulp vitality of the immature teeth involved in dental trauma or deep caries. Conventional root canal preparation of immature permanent teeth with necrotic pulp and apical pathosis presents several treatment challenges. Mechanical cleaning with instruments that remove dentin is contraindicated, because it may further weaken the already thin root canal walls $[4,8]$.

Obturation of the root canal without extending the root canal filling into periapical tissues is clinically challenging, even for the experienced clinician; the large apical opening that at times can have a divergent configuration does not provide the mechanical stop necessary to confine the filling material to the root canal. In 1966 Alfred L. Frank published an article describing a clinical technique aimed at inducing apical closure. By using repeated $\mathrm{Ca}(\mathrm{OH})_{2}$ dressings during a 3 - to 6-month period, he demonstrated that it was possible not only to induce healing of the apical lesion but also to induce closure of the root apex with calcified tissue (apexification). 
Hamad Faries Al Munjem et al; Saudi J Oral Dent Res, Jan, 2021; 6(1): 76-80

In some of the teeth in his case series, there was also continued formation of the root. In a subsequent series of articles by Torneck et al., these events appeared to be related not only to the ingress of a new population of cells but also to then stimulation of residual papilla and root sheath cells that survived the apical infection. Later, Cvek reported on the outcome of 55 nonvital permanent incisors treated by apexification and noted that in 50 incisors there were healing and apical closure but no continued root formation 14-21 months post treatment. He reported that the healing rate was dependent on the width of the apical foramen and the diameter of the periapical lesion. He concluded that the long-term outcome of apical closure and periapical healing had a high predictability rate.

However, apexification with $\mathrm{Ca}(\mathrm{OH}) 2$ has several disadvantages. It requires multiple visits during a long period of time (6-24 months; average, 1 year_7 months), it depends on the parents' commitment to ensure the child's dental visits are kept, and it undermines the mechanical strength of dentin because of a prolonged exposure to $\mathrm{Ca}(\mathrm{OH}) 2$ [10]. An alternative $\mathrm{Ca}(\mathrm{OH}) 2$ apexification was suggested by Torabinejad and Chivian. They suggested that cleaning the root canal and sealing the open apex with MTA in 1 or 2 visits could minimize the risk of root canal overfilling and promote apical repair. Simon et al assessed the outcome of this technique in only one appointment in teeth with open apices and apical lesions and concluded that it was a reasonable and predictable treatment alternative to $\mathrm{Ca}(\mathrm{OH})_{2}$ apexification.

Although this procedure offered a favorable healing outcome and required only one appointment, it still did little to improve on shortcomings of the $\mathrm{Ca}(\mathrm{OH}) 2$ apexification technique, namely the predisposition to root fracture and the failure to stimulate root development. These shortcomings prompted clinicians to continue the search for a procedure that promoted post-treatment pulp regeneration, dentin formation, and root development. Nygard Ostby, a pioneer of regenerative endodontic procedures in the early 1960s, showed that new vascularized tissue could be induced in the apical third of the root canal of endodontically treated mature teeth with necrotic pulps and apical lesions.

This was accomplished by the creation of a blood clot in the apical third of a cleaned and disinfected root canal by using an apically extended root canal file just before root canal filling. He proposed that through formation of a clot (scaffold), a vasculature could be established to support growth of new tissue into the unfilled portion of the root canal. He provided histologic evidence in support of his concept that was taken surgically from teeth that had been treated in this manner. Revascularization with continued root development and continued deposition of hard tissue in the root canal has also been shown to occur over time when immature teeth were reimplanted after intentional or traumatically related avulsion.

Extraoral time and degree of root maturation were shown to be important factors in the clinical success of this procedure. It became apparent that the larger the foramen, the greater is the opportunity for ingrowth of a new blood supply and the reestablishment of new tissue. It was also apparent that the shorter the extraoral time, the lesser is the risk of infection and hence the greater the chance for cells to retain their vitality $[1,10]$.

It appeared that the devascularized pulp acted as a matrix into which the new blood vessels and tissue could grow. Skoglund and Tronstad investigated changes that occurred in the root canal of replanted and auto transplanted immature teeth and reported that during the first 6 months there was an ingrowth of vascularized, cell-rich connective tissue throughout the entire root canal. After 6 months most teeth displayed a marked reduction in the number of cells and blood vessels and a newly formed a tubular hard tissue. In some teeth, a pulp with a functioning odontoblastic layer was present.

Cautious case assessment and precise pulpal diagnosis is significant in the treatment of immature teeth with pulpal injury. Clinical assessment of pulpal status requires a comprehensive history of subjective symptoms, thorough clinical and radiographic examination and carrying out diagnostic tests.

Precise pain history must be obtained. The duration, nature of the pain, aggravating and relieving factors must be considered. Duration of pain might vary, however pain that persist for more than a few seconds in a tooth with a vital pulp indicates irreversible pulpitis. When pain is spontaneous, severe and long lasting, this diagnosis is about certain.

If the pain is throbbing in nature and the tooth is tender to touch, pulpal necrosis with apical periodontitis or acute abscess is expected. Substantiation from objective tests is essential. These comprise visual examination, percussion testing and thermal and electric pulp testing. The existence of a swelling or sinus tract denotes pulpal necrosis and acute or chronic abscess. Tenderness to percussion indicates inflammation in the periapical tissues. In the immature teeth, pulp vitality testing usually gives erratic response because the sensory plexus of nerves in the sub odontoblastic region is not well developed as root formation is incomplete, and any injury to it give unreliable responses.

Over-dependence on the results of pulp vitality tests in immature teeth, especially the electric pulp testing is not suggested. Radiographic interpretation in these immature teeth with open apex can be 
challenging. In normal condition radiolucent area is present surrounding the developing apex of an immature tooth with a healthy pulp hence it is tricky to distinguish between this normal finding and a pathologic radiolucency due a necrotic pulp.

Comparing the periapical region with that of the contralateral tooth may be useful. Although it is not possible to set up a close association between the results of these vitality tests and the histological diagnosis, an accurate clinical diagnosis of pulpal vitality can be made in majority of cases by merging the outcome of the history, examination and diagnostic tests. When the pulp is judged to be vital, apexogenesis techniques can be performed. In case of a necrotic pulp, apexification is done $[2,9]$.

\begin{abstract}
Apexogenesis (root formation): Apexogenesis describes the continued physiologic development and formation of the root's apex in vital young permanent teeth. It can be achieved by implementing the appropriate vital pulp therapy techniques.
\end{abstract}

Apexification (root end closure): Apexification is a technique of inducing root end closure in an immature nonvital permanent tooth by removing the coronal and radicular tissue and placing a suitable biocompatible agent.

Indications: This procedure is indicated for nonvital immature permanent teeth.

\section{OBJECTIVES}

This procedure should induce apical barrier which can be confirmed by clinical and radiographic assessment. There should be no evidence of posttreatment adverse clinical signs or symptoms of pain, sensitivity, or swelling. Root fracture, lateral root pathosis or external root resorption should not be evident during or following therapy. In the past, techniques like custom fitting the filling material, paste fills and apical surgery were used for the management of non-vital immature teeth. Later the investigations focused on inducing apical closure using antibiotic and antiseptic pastes.

Calcium hydroxide: There are various products for inducing apical closure, but calcium hydroxide is the widely accepted material. Non-vital immature teeth undergoing apexification are first disinfected with irrigants like sodium hypochlorite and chlorhexidine then the canal is packed with calcium hydroxide paste for further disinfection and inducing apical closure by the formation of an apical calcific barrier. Kaiser in 1964 introduced the use of calcium hydroxide in apexification, he also stated that this material, when mixed with camphorated parachlorophenol would induce the formation of a calcified barrier across the apex.
Klein and Levy explained the successful induction of an apical barrier using calcium hydroxide and Cresatin (Premier Dental Products). When used as a root canal medicament Cresatin showed a minimal inflammatory potential and significantly less toxicity than camphorated parachlorophenol. Later investigators mixed calcium hydroxide with saline, sterile water or distilled water to further reduce the potential for cytotoxicity. Heithersay successfully used the combination Calcium hydroxide and methylcellulose (Pulpdent Corporation, Watertown, MA, USA).

Reduced solubility in tissue fluids and a rigid consistency are the two advantages of 'Pulpdent' over calcium hydroxide. Calcium hydroxide has antimicrobial action. The discharge of hydroxyl ions from calcium hydroxide damages the cellular component of bacteria by chemically altering the lipopolysaccharide. Various biological properties of bacteria are also affected [5-7].

Calcium hydroxide induces hard tissue formation, and early evidence suggests that high $\mathrm{pH}$ of calcium hydroxide may contribute to its osteoinductive property.

Histologically, the calcified tissue that forms over the apical foramen has been identified as an osteoid or cementoid material. The normal time required to attain apexification is 6-24 months (average 1 year \pm 7 months) however it can take up to 4years also. In dental literature there is difference on how often the canal should be refilled with Calcium hydroxide paste to produce apexification, and the decision appears to be empirical. According to Tronstad et al., refilling every 3-6 months is favoured.

Cohen \& Burns suggested refilling only if there is radiographic evidence of resorption of the paste. Chosack \& Cleaton-Jones suggested that after initial root filling with calcium hydroxide, there was nothing to be gained by its replacement either monthly or after 3 months for at least 6 months. Limitations of calcium hydroxide apexification are:

- Long time-span of the entire treatment;

- Multiple visits needed requiring patients cooperation and increased clinical costs

- Increased risk of tooth fracture using calcium hydroxide as a long-term root canal dressing These shortcomings led to the utilization of mineral trioxide aggregate to fill the apical end without the need for calcific barrier formation. Mineral trioxide aggregate: Mineral trioxide aggregate (MTA) was first developed by Torabinejad and members at the Loma Linda University, California, USA. Initially it was used as a root-end filling material in endodontic treatment $[1,2,8]$. 
It is a mixture of dicalcium silicate, tricalcium silicate, tricalcium aluminate, gypsum, tetracalcium aluminoferrite and bismuth oxide. Setting time of grey MTA differs with manufacturers, for Pro Root MTA it was reported to be $2 \mathrm{~h}$ and $45 \mathrm{~min}( \pm 5 \mathrm{~min})$ and MTAAngelus it was $10 \mathrm{~min}$.

MTA showed low solubility and a radiopacity that was little higher than that of dentin. It also demonstrated an excellent biocompatibility and sealing ability. Antimicrobial properties of MTA was related to its $\mathrm{pH}$, it has a $\mathrm{pH}$ of 12.5 comparable to that of calcium hydroxide. In comparison to Calcium hydroxide, MTA appears to be more predictable with consistent hardtissue formation. When MTA used for apexification, it shortens the treatment duration and produces more favorable results.

Many suggests one-visit apexification technique with MTA, which offers major advantage over traditional Calcium hydroxide methods. 8 One visit apexification:

One-visit apexification is defined as the nonsurgical condensation of a biocompatible material into the apical end of the root canal. The basis is to create an apical barrier that would facilitate the root canal to be filled instantly. Only an artificial apical stop is created and no effort to induce root end closure is taken. MTA acts as a scaffold for the formation of hard tissue and provides better biological seal.

In this technique thorough cleaning and shaping of the root canal system is done. Then, MTA is introduced as an apical seal followed by the immediate placement of a suitable bonded restoration within the root canal. Though the advances with MTA and bonded restorations show a better outcome, it cannot yield the result that apexogenesis can attain, i.e. maturation of the root end with better thickness of the root. Therefore, alternative approaches that allow the apical maturation should be pursued [5].

\section{A PARADIGM SHIFT IN THE MANAGEMENT OF PERMANENT IMMATURE TEETH}

A number of case reports have illustrated continued root development in treated necrotic immature teeth but, few cases have reported continued root development in teeth with infected root canal and draining sinus tracts. This is achieved through regenerative endodontic and revascularization procedures. These treatment procedures are termed as 'a paradigm shift' in the endodontic management of necrotic immature teeth. Initial studies suggests that, the continued root development in regenerative endodontic procedures are due to the part played by stem cells from pulp and periodontium.
For the success of these procedures triantibiotic pastes are generally used to eliminate the intra-radicular infection. The tri-antibiotic paste is usually a combination of ciprofloxacilin, metronidazole and minocycline. This combination of drugs has also been shown to be effective in eliminating bacteria in the deep layers of root canal dentine. Discoloration of the tooth is the main disadvantage of this combination and it is due to the presence of minocycline ${ }^{3}$.

It was suggested that calcium hydroxide may not be a suitable intra canal medicament in regenerative procedures because of the potential to form calcified tissue preventing the pulp from regeneration. Another concern is that Calcium hydroxide may damage the Hertwig's epithelial root sheath and destroys the surrounding undifferentiated cells that become odontoblasts.

Common factors and important observations in the success of regenerative endodontics are:

- The presence of a wide and open apex.

- Stem cell regenerative potential is high due to the young age of the patient.

- Care should be taken not to instrument the canal walls.

- Irrigation with sodium hypochlorite proves to be effective.

- Calcium hydroxide may not be a suitable intra canal medicament in regenerative procedures because of the potential to form calcified tissue preventing the pulp from regeneration. It also destroys viable cells that differentiate into odontoblasts.

- The use of a tri-antibiotic paste consisting of ciprofloxacin, metronidazole and minocycline is effective for eliminating bacteria from the infected root canal system.

- Blood clot formation allows tissue regeneration by acting as a protein scaffold.

- The use of MTA to complete the coronal seal which has known biological conductive properties to ensure an adequate coronal seal.

Some authors have suggested that the regenerative process may be initiated by the remaining viable pulpal tissue in necrotic teeth. A study on dog teeth has shown that these tissues originate from the periodontal ligament and consists of dentine, cementum and bone like material rather than pulp tissue with only a $30 \%$ chance of pulp tissue re-entering the pulp space [11].

\section{CONCLUSION}

Compared to calcium hydroxide, MTA is effective in treating immature permanent teeth with necrotic pulps with the advantage of reduced treatment time and more predictable barrier formation. The shortcoming is similar to calcium hydroxide that the 
placement of an apical plug does not account for continued root development along the entire root length.

Complete root development is possible with regenerative endodontic procedures, and there is a paradigm shift in the endodontic management of immature permanent teeth with necrotic pulps using regenerative endodontic procedures. In future conventional apexification procedures might be replaced completely by these newer methods.

\section{REFERENCES}

1. American Association of Endodontists. (2003). Glossary of endodontic terms, 7th edn. Chicago: American Association of Endodontists.

2. Shabahang, S. (2013). Treatment options: apexogenesis and apexification. Pediatric dentistry, 35(2), 125-128.

3. Klein H. Pulp response to an electric pulp stimulator in the developing permanent anterior dentition. J Dent Child 1978; 45:23-5.

4. Rafter, M. (2005). Apexification: a review. Dental Traumatology, 21(1), 1-8.

5. American Academy of Pediatric Dentistry clinical Guideline on Pulp Therapy for Primary and
Immature Permanent Teeth. Reference manual. 2009;33:11-12.

6. Cooke, C. (1960). Root canal therapy in non-vital teeth with open apices. Br Dent J, 108, 147-150.

7. Ball, J. S. (1964). Apical root formation on nonvital immature permanent incisor. Br Dent J, 116, 166-167.

8. Huang, G. J. (2009). Apexification: the beginning of its end. International endodontic journal, 42(10), 855-866.

9. Heithersay, G. S. (1975). Calcium hydroxide in the treatment of pulpless teeth with associated pathology. International endodontic journal, 8(2), 74-93.

10. Jiang, J., Zuo, J., Chen, S. H., \& Holliday, L. S. (2003). Calcium hydroxide reduces lipopolysaccharide-stimulated osteoclast formation. Oral Surgery, Oral Medicine, Oral Pathology, Oral Radiology, and Endodontology, 95(3), 348-354.

11. Javelet, J., Torabinejad, M., \& Bakland, L. K. (1985). Comparison of two $\mathrm{pH}$ levels for the induction of apical barriers in immature teeth of monkeys. Journal of endodontics, 11(9), 375-378. 